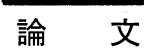

\title{
事象と状態の部分観測のもとでの離散事象 システムのスーパバイザ制御*
}

高井 重昌 ${ }^{* *}$. 潮 俊光 ${ }^{* *}$. 児玉 慎三**

\author{
Supervisory Control of Discrete Event Systems \\ under Partial Observations of Events and States*
}

Shigemasa TAKaI**, Toshimitsu Ushio** and Shinzo Kodama**

\begin{abstract}
In this paper, we study supervisory control of discrete event systems under partial observations. Most of the research on supervisory control considers a supervisor which takes a control action according to only event sequences. This paper proposes a supervisor which selects a control pattern based upon partial observations of events and states. We first derive necessary and sufficient conditions under which there exists a supervisor for a given language, namely, a control specification. It is shown that our supervisor is more powerful than a supervisor which uses only event sequences. Next, we study the case that there does not exist a supervisor for a given language. We present a sublanguage of a given language for which a supervisor exists.
\end{abstract}

\section{1. 緒 論}

並行処理制御，排他制御など離散事象システムにおけ る多くの論理的な制御問題は, 制御仕様として与えられた 言語を生成するようにシステムを制御する問題に帰着で きる ${ }^{1,2)}$. この問題に対する制御手法として, Ramadge と Wonham によって提案されたスーパバイザ制御 ${ }^{3)}$ が 有効である．彼らが考察したスーパバイザは，システム で生成された事象列から制御パターンへの写像として定 義される3).つまりスーパバイザは, システムで生成さ れた事象列を観測し，それに基づいて，次に生起を許容 する事象を決定する制御器として定義されている. しか し一般に，すべての事象が完全に観測できるとは限ら ない.このような事象の部分観測のもとでのスーパバイ ザ制御についてもすでに考察されており，スーパバイザ が存在するための必要十分条件 $\left.{ }^{4)}, 5\right)$, およびスーパバイ ザが存在するような部分言語の構成法が求められてい $ろ^{6) \sim 10)}$.

* 原稿受付 1994 年 8 月 29 日

** 大阪大学 工学部 Department of Electronic Engineering, Osaka University ; 2-1 Yamadaoka, Suita city, Osaka 565, JAPAN

Key Words : discrete event system, supervisory control, partial observation, automaton, formal language.
またLiとWonham は, 事象と状態が完全に観測可 能であるという仮定のもとで, メモリと呼ばれる動的要 素を用いた制御器を提案している11). 特にベクトル離散 事象システムにおいて, メモリ付き制御器が, 従来の スーパバイザよりも効率的に構成できることを示してい る ${ }^{12)}$. しかし本論文で示すように，事象が完全に観測可 能であるならば, 事象と状態の両方の観測列を用いたス 一パバイザが構成できる言語のクラスは，従来のスーパ バイザが構成できるクラスと等しくなる.

本論文では, 部分観測のもとで, 事象と状態の両方の 観測列を利用したスーパバイザについて考察する．まず， 与えられた制御仕様を満たすスーパバイザが存在するた めの必要十分条件を示す。そして, 従来のスーパバイザ が構成できる言語のクラスよりもより広いクラスに対し て, 本論文で提案するスーパバイザが構成できることを 示す.しかし，一般に与えられた言語に対して，常にス 一パバイザが存在するとは限らない. そこで, 与えられ た言語に対して，スーパバイザが存在するようなその部 分言語を与える.

\section{2. 準 備}

対象システム $G$ は (1) 式で表わされるオートマトン ${ }^{13)}$ でモデル化されているとする. 


$$
G=\left(X, \Sigma, \delta, x_{0}\right)
$$

ただし， $X$ は状態の集合， $x_{0}$ は初期状態， $\Sigma$ は事象の 有限集合, $\delta: \Sigma \times X \rightarrow X$ は状態遷移関数である。一般 に $\delta$ は部分関数である. $\Sigma^{*}$ と $X^{*}$ をそれぞれ, 空列 $\varepsilon$ を含む, $\Sigma$ と $X$ の要素からなるすべての有限列の集合 とする. 状態遷移関数 $\delta$ は, 以下のように $\delta: \Sigma^{*} \times X \rightarrow$ $X$ に拡張できる.

- $\delta(\varepsilon, x)=x$

- 任意の $s \in \Sigma^{*}$ と任意の $\sigma \in \Sigma$ に対して, $\delta(s, x)$ が定義されているとき,

$$
\delta(s \sigma, x)=\delta(\sigma, \delta(s, x))
$$

である。

以下 $s \in \Sigma^{*}$ と $x \in X$ に対して, $\delta(s, x)$ が定義されて いるとき, $\delta(s, x)$ ! と書く.

$L(G)$ は $G$ によって生成される言語を表わし,

$$
L(G)=\left\{s \in \Sigma^{*} \mid \delta\left(s, x_{0}\right) !\right\}
$$

と定義される.

そして $G$ によって生成される状態列の集合 $T(G) \subseteq$ $X^{*}$ を以下で定義する. まず写像 $\pi: L(G) \rightarrow X^{*}$ を以 下のように帰納的に定義する.

- $\pi(\varepsilon)=x_{0}$

- 任意の $s \sigma \in L(G)(\sigma \in \Sigma)$ に対して,

$$
\pi(s \sigma)=\pi(s) \delta\left(s \sigma, x_{0}\right)
$$

\section{である。}

つまり $\pi(s)$ は事象列 $s \in L(G)$ の生起によってシステ ムがとる状態列を表わす。そして $T(G)$ を次式で定義 する.

$$
T(G)=\left\{w \in X^{*} \mid \exists s \in L(G) ; \pi(s)=w\right\}
$$

実システムにおいては，一般にすべての事象と状態が 完全に観測できるとは限らない. $M_{l}: \Sigma \rightarrow \Lambda$ と $M_{t}$ : $X \rightarrow Y$ をそれぞれ事象と状態に関するマスクとする ${ }^{5), 11)}$. ここで $\Lambda$ と $Y$ はそれぞれスーパバイザと呼ばれる（外 部の）コントローラによって観測される事象と状態の集 合である. $M_{l}$ は以下のように $\Sigma^{*}$ に関する関数に拡張 できる.

- $M_{l}(\varepsilon)=\varepsilon$

- 任意の $s \sigma \in \Sigma^{*}(\sigma \in \Sigma)$ に対して,

$$
M_{l}(s \sigma)=M_{l}(s) M_{l}(\sigma)
$$

である。

$M_{t}$ も同様に拡張できる.

本論文では Ramadge-Wonham のモデルを考える ${ }^{3)}$. すなわち， $\Sigma$ はその生起をスーパバイザによって禁止 できる事象の集合 $\Sigma_{c}$ と, 禁止できない事象の集合 $\Sigma_{u}$
に分割できる。ただし， $\Sigma=\Sigma_{c} \cup \Sigma_{u}, \Sigma_{c} \cap \Sigma_{u}=\phi$ であ る. $\Sigma_{u}$ を含む $\Sigma$ の部分集合を制御パターンと言い，制 御パターンの集合を $\Gamma$ とおく。つまり,

$$
\Gamma=\left\{\gamma \in 2^{\Sigma} \mid \Sigma_{u} \subseteq \gamma \subseteq \Sigma\right\}
$$

である.ここで $2^{\Sigma}$ は $\Sigma$ のべき集合を表わす.

従来の部分観測のあとでのスーパバイザ制御において は，スーパバイザは事象の観測列のみに基づき，次の制御 パターンを決定する制御器と定義されていた．そこで本 論文では，スーパバイザ $S: M_{l}(L(G)) \times M_{t}(T(G)) \rightarrow$ $\Gamma$ を事象と状態両方の観測列に基づき, 次の制御パター ンを決定する制御器と定義する。そして次に $G$ におい て生起可能な事象は，このスーパバイザによって与えら れた制御パターンの要素に限られる.すなわち制御パ夕 ーンの要素でない事象は, その生起が禁止される.この ようにして, 次に生起可能な事象を制限することにより, システムが望ましい振る舞いをするように制御する。こ のような制御システムのブロック線図を Fig. 1 に示す.

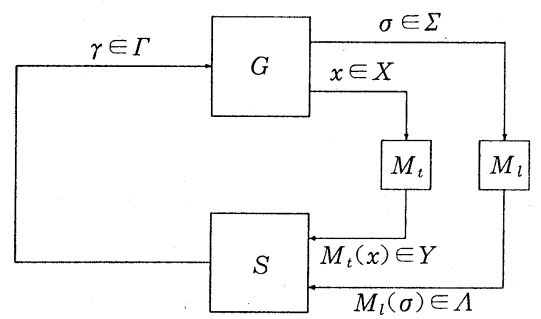

Fig. 1 A block diagram of the closed-loop system スーパバイザ $S$ を施した閉ループシステムを $S \mid G$ と 書く. $S \mid G$ において生成される言語 $L(S \mid G)$ は次のよ うに帰納的に定義される.

- $\varepsilon \in L(S \mid G)$

- 任意の $s \in L(S \mid G)$ と任意の $\sigma \in \Sigma$ に対して,

$$
\begin{aligned}
& s \sigma \in L(S \mid G) \\
& \quad \Leftrightarrow s \sigma \in L(G) \wedge \sigma \in S\left(M_{l}(s), M_{t}(\pi(s))\right)
\end{aligned}
$$

である.

言語 $K \subseteq \Sigma^{*}$ に対して，そのすべての接頭語の集合を 言とおく.すなわち

$$
\bar{K}=\left\{s \in \Sigma^{*} \mid \exists t \in \Sigma^{*} ; s t \in K\right\}
$$

である.そして $K=\bar{K}$ であるとき， $K$ は閉じていると いう。明らかに $L(G)$ 之 $L(S \mid G)$ は閉じている.

言語 $K \subseteq L(G)$ が次の条件を満たすとき， $K$ は $\left(\Sigma_{u}, L(G)\right)$-不変であると言う ${ }^{3), 5)}$.

- 任意の $s \in \bar{K}$ と任意の $\sigma \in \Sigma_{u}$ に対して,

$$
s \sigma \in L(G) \Rightarrow s \sigma \in \bar{K}
$$

すなわち， $\bar{K} \Sigma_{u} \cap L(G) \subseteq \bar{K}$ である. 
また次の条件が満たされるとき, $K$ は $\left(M_{l}, \Sigma_{c}, L(G)\right)$ 可制御であるという5).

- 任意の $s, s^{\prime} \in K$ と任意の $\sigma \in \Sigma_{c}$ に対して,

$$
\begin{aligned}
M_{l}(s) & =M_{l}\left(s^{\prime}\right) \wedge s \sigma \in K \wedge s^{\prime} \sigma \in L(G) \\
& \Rightarrow s^{\prime} \sigma \in K
\end{aligned}
$$

である.

そして制御仕様として与えられた空でない閉じた言語 $K \subseteq L(G)$ に対して, $L\left(S^{\prime} \mid G\right)=K$ なる事象の観測列 のみを用いたスーパバイザ $S^{\prime}: M_{l}(L(G)) \rightarrow \Gamma$ が存在 するための必要十分条件は, $K$ が $\left(\Sigma_{u}, L(G)\right)$-不变か つ $\left(M_{l}, \Sigma_{c}, L(G)\right)$-可制御となることである ${ }^{4), 5)}$.

(注意) 参考文献では, 事象に関するマスク $M_{l}$ は $M_{l}: \Sigma \rightarrow \Lambda \cup\{\varepsilon\}$ として定義されている.すなわち, ある事象の生起がまったく観測できない場合も考慮され ている，そして本論文で得られるすべての結果は，この 場合にあ適用できる。しかし実用上以下のような問題点 がある.

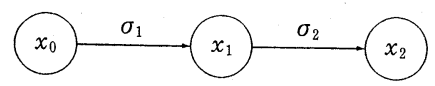

Fig. 2 An automaton

Fig. 2 に示されるオートマトンを考える.ここで, $\Sigma=\Sigma_{c}=\left\{\sigma_{1}, \sigma_{2}\right\}, X=\left\{x_{0}, x_{1}, x_{2}\right\}$ である. そしてマ スク $M_{l}$ と $M_{t}$ は次式で与えられるとする.

$$
\begin{aligned}
& M_{l}(\sigma)= \begin{cases}\varepsilon, & \text { if } \sigma=\sigma_{1} \\
\sigma_{2}, & \text { if } \sigma=\sigma_{2}\end{cases} \\
& M_{t}(x)=y, \quad \forall x \in X
\end{aligned}
$$

そして $K=\left\{\varepsilon, \sigma_{1}\right\}$ なる $K \subseteq L(G)$ を考える．このとき 次式で与えられるスーパバイザ $S$ に対して $L(S \mid G)=$ Kとなる。

$$
S(d, e)= \begin{cases}\phi, & \text { if } d=\varepsilon \wedge e=y y \\ \Sigma, & \text { otherwise }\end{cases}
$$

このスーパバイザは， $x_{0} に$ においてすべての事象の生起 を許可し， $\sigma_{1}$ の生起により遷移した $x_{1}$ において, $S\left(M_{l}\left(\sigma_{1}\right), M_{t}\left(\pi\left(\sigma_{1}\right)\right)\right)=S(\varepsilon, y y)=\phi$ より, 制御 パターンを切り替え, すべての事象の生起を禁止する.

しかし実際には， $\sigma_{1}$ の生起が観測できず，しかも状態 の観測值む变化しないため， $\sigma_{1}$ の生起に関する情報を スーパバイザは得ることができず，制御パターンを切り 替えることができない。

よって本論文で提案したスーパバイザ制御が寒用上可 能となるためには, “何らかの事象が生起した”という 情報を少なくとあ得ること，すなわち $M_{l}^{-1}(\varepsilon)=\phi$ であ ることが必要である。したがって本論文では， $M_{l}$ を
$M_{l}: \Sigma \rightarrow \Lambda$ と定義している.

\section{3. スーパバイザの存在条件}

本節では, 与えられた言語 $K \subseteq L(G)$ に対して, $L(S \mid G)=K$ なる事象之状態両方の観測列を用いた スーパバイザ $S: M_{l}(L(G)) \times M_{t}(T(G)) \rightarrow \Gamma$ が存在 するための必要十分条件を求める。 まず言語の $\left(M_{l}\right.$, $\left.M_{t}, \Sigma_{c}, L(G)\right)$-可制御性の概念を導入する.

【定義 1】言語 $K \subseteq L(G)$ が次の条件を満たすとき, $K$ は $\left(M_{l}, M_{t}, \Sigma_{c}, L(G)\right)$-可制御であるという.

- 任意の $s, s^{\prime} \in K$ 之任意の $\sigma \in \Sigma_{c}$ に対して,

$$
\begin{aligned}
& M_{l}(s)=M_{l}\left(s^{\prime}\right) \wedge M_{t}(\pi(s))=M_{t}\left(\pi\left(s^{\prime}\right)\right) \\
& \wedge s \sigma \in K \wedge s^{\prime} \sigma \in L(G) \\
\Rightarrow & s^{\prime} \sigma \in K
\end{aligned}
$$

である.

状態に関するマスク $M_{t}$ が定值関数であるならば, $\left(M_{l}, M_{t}, \Sigma_{c}, L(G)\right)$-可制御性は $\left(M_{l}, \Sigma_{c}, L(G)\right)$-可 制御性と等価になる。

【定理 1】空でない閉じた言語 $K \subseteq L(G)$ に対して, $L(S \mid G)=K$ なるスーパバイザ $S: M_{l}(L(G)) \times$ $M_{t}(T(G)) \rightarrow \Gamma$ が存在するための必要十分条件は, $K$ が $\left(\Sigma_{u}, L(G)\right)$-不変かつ $\left(M_{l}, M_{t}, \Sigma_{c}, L(G)\right)$-可制御 となることである.

（証明）まず十分性を証明する，次式で与えられる スーパバイザ $S: M_{l}(L(G)) \times M_{t}(T(G)) \rightarrow \Gamma$ を考 える.

$$
\begin{aligned}
& S(d, e) \\
& =\left\{\begin{array}{l}
\Sigma_{u} \cup \Sigma_{c}(d, e), \\
\quad \text { if } \exists s \in K ; M_{l}(s)=d \wedge M_{t}(\pi(s))=e \\
\Sigma, \quad \text { otherwise }
\end{array}\right. \\
& \begin{array}{l}
\Sigma_{c}(d, e) \\
=\left\{\sigma \in \Sigma_{c} \mid \exists s \in K ; M_{l}(s)=d \wedge M_{t}(\pi(s))=e\right. \\
\wedge s \sigma \in K\}
\end{array}
\end{aligned}
$$$$
\text { ただし }
$$

である.この $S$ に対して $L(S \mid G)=K$ となることを 示す. $L(S \mid G)$ と $K$ は共に空でなく閉じているので, $\varepsilon \in L(S \mid G) \cap K$ である. $s \in L(S \mid G) \cap K$ なる $s \in$ $\Sigma^{*}$ を考える. まず $s \sigma \in L(S \mid G)$ であると仮定する.

そのとき, $L(S \mid G)$ の定義より，

$$
\begin{aligned}
& \sigma \in S\left(M_{l}(s), M_{t}(\pi(s))\right) \\
& \quad=\Sigma_{u} \cup \Sigma_{c}\left(M_{l}(s), M_{t}(\pi(s))\right)
\end{aligned}
$$

かつ $s \sigma \in L(G)$ である. $K$ は $\left(\Sigma_{u}, L(G)\right)$-不変であ るから， $\sigma \in \Sigma_{u}$ ならば $s \sigma \in K$ である。 $\sigma \in \Sigma_{c}$ の 
場合を考える. このとき, $M_{l}(t)=M_{l}(s), M_{t}(\pi(t))=$ $M_{t}(\pi(s))$ かつ $t \sigma \in K$ なる $t \in K$ が存在する. そして $K$ は $\left(M_{l}, M_{t}, \Sigma_{c}, L(G)\right)$-可制御であるから, $s \sigma \in K$ である.よって $L(S \mid G) \subseteq K$ が成り立つ. 逆に $s \sigma \in K$ であると仮定する. $K \subseteq L(G)$ であるから, $s \sigma \in L(G)$ である。あし $\sigma \in \Sigma_{u}$ ならば, $\sigma \in S\left(M_{l}(s), M_{t}(\pi(s))\right)$ であり， $s \sigma \in L(S \mid G)$ を得る. また $\sigma \in \Sigma_{c}$ ならば,

$$
\sigma \in \Sigma_{c}\left(M_{l}(s), M_{t}(\pi(s))\right) \subseteq S\left(M_{l}(s), M_{t}(\pi(s))\right)
$$

となり， $s \sigma \in L(S \mid G)$ である. ゆえに $K \subseteq L(S \mid G)$ が成り立つ。

つぎに, 必要性を証明する. まず $K$ が $\left(\Sigma_{u}, L(G)\right)$-不 変であることを示す. $s \sigma \in L(G)$ なる $s \in K$ と $\sigma \in \Sigma_{u}$ を考える. このとき, $s \in L(S \mid G)$ かつ $\sigma \in S\left(M_{l}(s)\right.$, $\left.M_{t}(\pi(s))\right)$ であるから, $s \sigma \in L(S \mid G)=K$ を得る. つぎに, $K$ が $\left(M_{l}, M_{t}, \Sigma_{c}, L(G)\right)$-可制御であるこ とを示す. $M_{l}(s)=M_{l}\left(s^{\prime}\right), M_{t}(\pi(s))=M_{t}\left(\pi\left(s^{\prime}\right)\right)$, $s \sigma \in K$ かつ $s^{\prime} \sigma \in L(G)$ なる $s, s^{\prime} \in K$ と $\sigma \in \Sigma_{c}$ を 考える.このとき, $s, s^{\prime}, s \sigma \in L(S \mid G)$ であることか ら, $\sigma \in S\left(M_{l}(s), M_{t}(\pi(s))\right)$ を得る. そして $M_{l}(s)=$ $M_{l}\left(s^{\prime}\right)$ かつ $M_{t}(\pi(s))=M_{t}\left(\pi\left(s^{\prime}\right)\right)$ であるから, $\sigma \in$ $S\left(M_{l}\left(s^{\prime}\right), M_{t}\left(\pi\left(s^{\prime}\right)\right)\right)$ である. ゆえに, $s^{\prime} \in L(S \mid G)$ かつ $s^{\prime} \sigma \in L(G)$ であることから， $s^{\prime} \sigma \in L(S \mid G)=K$ となる。

明らかに，与えられた言語 $K \subseteq L(G)$ が $\left(M_{l}, \Sigma_{c}\right.$, $L(G))$-可制御ならば, $\left(M_{l}, M_{t}, \Sigma_{c}, L(G)\right)$-可制御 である。しかし一般に逆の関係は成り立たない。すなわ ち事象と状態両方の観測列を用いたスーパバイザは構成 できるが，従来の事象の観測列のみを用いたスーパバイ ザは構成できない場合がある．Fig. 3 に示されるオ一 トマトンを考える.ここで, $\Sigma=\Sigma_{c}=\left\{\sigma_{1}, \sigma_{2}, \sigma_{3}\right\}$, $X=\left\{x_{0}, x_{1}, x_{2}, x_{3}, x_{4}, x_{5}\right\}$ である. そしてマスク $M_{l}$ 之 $M_{t}$ は次式で与えられるとする.

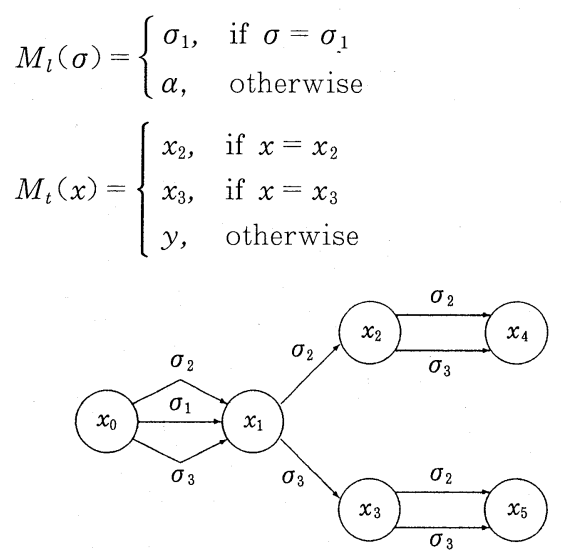

Fig. 3 An automaton
そして $K=\overline{\sigma_{1} \sigma_{2} \sigma_{3}+\sigma_{1} \sigma_{3} \sigma_{2}}$ なる $K \subseteq L(G)$ を考え る. $\Sigma_{u}=\phi$ であるから, 明らかに $K$ は $\left(\Sigma_{u}, L(G)\right)-$ 不変である. しかし, $\sigma_{1} \sigma_{2}, \sigma_{1} \sigma_{3} \in K, M_{l}\left(\sigma_{1} \sigma_{2}\right)=$ $M_{l}\left(\sigma_{1} \sigma_{3}\right), \sigma_{1} \sigma_{2} \sigma_{3} \in K$ かつ $\sigma_{1} \sigma_{3} \sigma_{3} \notin K$ であるから, $K$ は $\left(M_{l}, \Sigma_{c}, L(G)\right)$-可制御ではない。しかし, $M_{t}\left(\pi\left(\sigma_{1} \sigma_{2}\right)\right)=y y x_{2}, M_{t}\left(\pi\left(\sigma_{1} \sigma_{3}\right)\right)=y y x_{3}$ より, $M_{t}\left(\pi\left(\sigma_{1} \sigma_{2}\right)\right) \neq M_{t}\left(\pi\left(\sigma_{1} \sigma_{3}\right)\right)$ である. そして $K$ は $\left(M_{l}, M_{t}, \Sigma_{c}, L(G)\right)$-可制御であることが容易に示さ れる.よって定理 1 より, $L(S \mid G)=K$ なるスーパバ イザ $S: M_{l}(L(G)) \times M_{t}(T(G)) \rightarrow \Gamma$ が存在する.

さらに一般に, 本節で考察した問題は従来の事象の観 測列のみを用いたスーパバイザ制御問題 ${ }^{4)}$,5) には帰着で きない.すなわち， $M_{l}$ と $M_{t}$ が与えられたとき，

$C_{l t}\left(M_{l}, M_{t}, L(G)\right)$ $:=\left\{K \subseteq L(G) \mid \exists S: M_{l}(L(G)) \times M_{t}(T(G)) \rightarrow \Gamma\right.$

$C_{l}\left(M_{l}, L(G)\right)$ $; L(S \mid G)=K\}$

$$
\begin{aligned}
:=\left\{K^{\prime} \subseteq L(G) \mid \exists S^{\prime}: M_{l}(L(G))\right. & \rightarrow \Gamma \\
& \left.; L\left(S^{\prime} \mid G\right)=K^{\prime}\right\}
\end{aligned}
$$

とおくと, $C_{l t}\left(M_{l}, M_{t}, L(G)\right)=C_{l}\left(M_{l}^{\prime}, L(G)\right)$ とな る $M_{l}^{\prime}$ は一般に存在しない.

たとえば, Fig. 3 に示したシステムにおいて, 上述し たように, $K=\overline{\sigma_{1} \sigma_{2} \sigma_{3}+\sigma_{1} \sigma_{3} \sigma_{2}}$ に対して, $L(S \mid G)=$ $K$ なるスーパバイザ $S: M_{l}(L(G)) \times M_{t}(T(G)) \rightarrow \Gamma$ が存在する.一方, $K$ が $\left(M_{l}^{\prime}, \Sigma_{c}, L(G)\right)$-可制御である ためには， $M_{l}^{\prime}\left(\sigma_{2}\right) \neq M_{l}^{\prime}\left(\sigma_{3}\right)$ でなければならない.この ような $M_{l}^{\prime}$ に対して, $K^{\prime}=\overline{\sigma_{2} \sigma_{2}+\sigma_{3} \sigma_{3}}$ は $\left(\Sigma_{u}, L(G)\right)-$ 不変かつ $\left(M_{l}^{\prime}, \Sigma_{c}, L(G)\right)$-可制御である. 一方, $\sigma_{2}$, $\sigma_{3} \in K^{\prime}, M_{l}\left(\sigma_{2}\right)=M_{l}\left(\sigma_{3}\right), M_{t}\left(\pi\left(\sigma_{2}\right)\right)=M_{t}\left(\pi\left(\sigma_{3}\right)\right)$, $\sigma_{2} \sigma_{2} \in K^{\prime}$ かつ $\sigma_{3} \sigma_{2} \notin K^{\prime}$ であるから, $K^{\prime}$ は $\left(M_{l}, M_{t}\right.$, $\left.\Sigma_{c}, L(G)\right)$-可制御ではない. すなわち $C_{l t}\left(M_{l}, M_{t}\right.$, $L(G)) \neq C_{l}\left(M_{l}^{\prime}, L(G)\right)$ となる．注意すべき点は， $C_{l t}\left(M_{l}, M_{t}, L(G)\right) \subseteq C_{l}\left(M_{l}^{\prime}, L(G)\right)$ となる $M_{l}^{\prime}$ は常 に存在しているが，等号が成立するような $M_{l}^{\prime}$ の存在は 保証されないという点である。このことは，本論文で提 案した制御系が真に新しい機構であることを示している.

最後に特別な場合としてすべての事象が完全に観測可 能である場合を考える.すなわち $M_{l}$ が

$$
M_{l}(\sigma)=\sigma, \quad \forall \sigma \in \Sigma
$$

で与えられる場合を考える。このとき任意の $s, s^{\prime} \in$ $L(G)$ に対して, $M_{l}(s)=M_{l}\left(s^{\prime}\right)$ ならば $s=s^{\prime}$ である. よって任意の $K \subseteq L(G)$ は $\left(M_{l}, M_{t}, \Sigma_{c}, L(G)\right)$ 一可制 御であることがわかる。 よって定理 1 の条件は従来の事 象の観測列のみを用いたスーパバイザの存在条件 ${ }^{3)}$ と等 価となる。 
要約すれば, 空でない閉じた $\left(\Sigma_{u}, L(G)\right)$-不変な言 語が, $\left(M_{l}, \Sigma_{c}, L(G)\right)$-可制御ならば, 従来の事象の 観測列のみを用いたスーパバイザが構成できる。そして, $\left(M_{l}, \Sigma_{c}, L(G)\right)$-可制御ではないが, $\left(M_{l}, M_{t}, \Sigma_{c}\right.$, $L(G))$ 一可制御となるならば, 従来のスーパバイザは構 成できないが, 本論文で提案したスーパバイザは構成で きることになる，ただし，すべての事象が完全に観測可 能な場合には, 上述のように, 本論文で提案したスーパ バイザが構成できる言語のクラスと従来のスーパバイザ が構成できるクラスは等価となる。

\section{4. スーパバイザが存在する部分言語}

定理 1 において，与えられた言語に対してスーパバイ ザが存在するための必要十分条件を示した。しかし，一 般にその条件が満たされるとは限らない。このような場 合には, 与えられた言語に対して, 定理 1 の条件を満た すその部分言語を求め, それに対してスーパバイザを構 成することになる.

言語 $K \subseteq L(G)$ に対して, その定理 1 の条件を満たす, すなわち $\left(\Sigma_{u}, L(G)\right)$-不变かつ $\left(M_{l}, M_{t}, \Sigma_{c}, L(G)\right)$ 可制御である閉じた部分言語の集合を $A(K)$ と書く. $\phi \in A(K)$ より, $A(K)$ は空ではない. $\left(M_{l}, \Sigma_{c}, L(G)\right)-$ 可制御な言語の集合は一般に和に関して閉じないことが すでに示されている(4),5). よって明らかに， $\left(M_{l}, M_{t}\right.$, $\left.\Sigma_{c}, L(G)\right)$-可制御な言語の集合屯一般に和に関して閉 じていない，このことより， $A(K)$ あ一般に和に関し

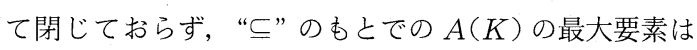
一般に存在しない。参考文献 4), 5) では, $\left(M_{l}, \Sigma_{c}\right.$, $L(G))$-可制御性よりあ厳しい条件である, $\left(M_{l}, L(G)\right)$ recognizability の概念が導入され， $\left(\Sigma_{u}, L(G)\right)$-不変 かつ $\left(M_{l}, L(G)\right)$-recognizable な閉じた言語の集合 は和に関して閉じることが証明されている。そしてその 集合の最大要素に対する, (事象の観測列のみを用いた) スーパバイザの構成法が与えられている。 そこで本節で は, $\left(M_{l}, M_{t}, L(G)\right)$-recognizable な言語を定義し, $K の\left(\Sigma_{u}, L(G)\right)$-不変, $\left(M_{l}, M_{t}, \Sigma_{c}, L(G)\right)$-可制御 かっ $\left(M_{l}, M_{t}, L(G)\right)$-recognizable である閉じた部 分言語の集合の最大要素に対して, 事象と状態両方の観 測列を用いたスーパバイザが存在することを示す.

【定義 2】言語 $K \subseteq L(G)$ が以下の条件を満たすと き, $K$ は $\left(M_{l}, M_{t}, L(G)\right)$-recognizable であるという.

- 任意の $s, s^{\prime} \in L(G)$ に対して,

$$
\begin{aligned}
M_{l}(s) & =M_{l}\left(s^{\prime}\right) \wedge M_{t}(\pi(s))=M_{t}\left(\pi\left(s^{\prime}\right)\right) \\
& \wedge s \in K \Rightarrow s^{\prime} \in K
\end{aligned}
$$

である.
状態に関するマスク $M_{t}$ が定值関数であるならば, $\left(M_{l}, M_{t}, L(G)\right)$-recognizability は $\left(M_{l}, L(G)\right)$ recognizability と等価になる。しかし任意の $\left(M_{l}\right.$, $L(G))$-recognizable な言語は $\left(M_{l}, \Sigma_{c}, L(G)\right)$-可制 御であるが，一般に $\left(M_{l}, M_{t}, L(G)\right)$-recognizable な 言語は $\left(M_{l}, M_{t}, \Sigma_{c}, L(G)\right)$-可制御とはならない. Fig. 4 に示されるオートマトンを考える. ここで, $\Sigma=$ $\Sigma_{c}=\left\{\sigma_{1}, \sigma_{2}, \sigma_{3}\right\}, X=\left\{x_{0}, x_{1}, x_{2}, x_{3}, x_{4}\right\}$ である. そ してマスク $M_{l}$ と $M_{t}$ は次式で与えられるとする.

$$
\begin{aligned}
& M_{l}(\sigma)= \begin{cases}\sigma_{3}, & \text { if } \sigma=\sigma_{3} \\
\alpha, & \text { otherwise }\end{cases} \\
& M_{t}(x)= \begin{cases}x, & \text { if } x \in\left\{x_{0}, x_{3}, x_{4}\right\} \\
y, & \text { otherwise }\end{cases}
\end{aligned}
$$

そして $K=\overline{\sigma_{1} \sigma_{3}+\sigma_{2}}$ なる $K \subseteq L(G)$ を考える.この とき $K$ が $\left(M_{l}, M_{t}, L(G)\right)$-recognizable であること は容易に示される。しかし， $\sigma_{1}, \sigma_{2} \in K, M_{l}\left(\sigma_{1}\right)=$ $M_{l}\left(\sigma_{2}\right), M_{t}\left(\pi\left(\sigma_{1}\right)\right)=M_{t}\left(\pi\left(\sigma_{2}\right)\right), \sigma_{1} \sigma_{3} \in K$ かつ $\sigma_{2} \sigma_{3} \notin K$ であるから, $K$ は $\left(M_{l}, M_{t}, \Sigma_{c}, L(G)\right)$-可 制御ではない。

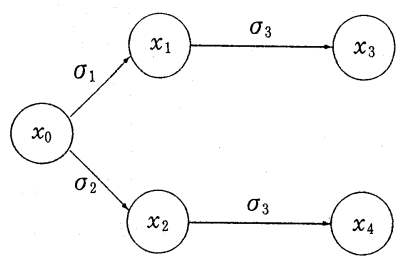

Fig. 4 An automaton

【命題 1】以下の条件 C が成り立つとする。このとき, 任意の $\left(M_{l}, M_{t}, L(G)\right)$-recognizable である言語 $K \subseteq L(G)$ は $\left(M_{l}, M_{t}, \Sigma_{c}, L(G)\right)$-可制御である.

条件 C 任意の $x, x^{\prime} \in X$ と任意の $\sigma \in \Sigma$ に対して,

$$
\begin{aligned}
M_{t}(x)= & M_{t}\left(x^{\prime}\right) \wedge \delta(\sigma, x) ! \wedge \delta\left(\sigma, x^{\prime}\right) ! \\
& \Rightarrow M_{t}(\delta(\sigma, x))=M_{t}\left(\delta\left(\sigma, x^{\prime}\right)\right)
\end{aligned}
$$

である.

(証明) $M_{l}(s)=M_{l}\left(s^{\prime}\right), M_{t}(\pi(s))=M_{t}\left(\pi\left(s^{\prime}\right)\right)$, $s \sigma \in K$ 加 $s^{\prime} \sigma \in L(G)$ なる $s, s^{\prime} \in K$ と $\sigma \in \Sigma_{c}$ を 考える.このとき, 明らかに $M_{l}(s \sigma)=M_{l}\left(s^{\prime} \sigma\right)$ であ る. また $M_{t}(\pi(s))=M_{t}\left(\pi\left(s^{\prime}\right)\right)$ より, $M_{t}\left(\delta\left(s, x_{0}\right)\right)=$ $M_{t}\left(\delta\left(s^{\prime}, x_{0}\right)\right)$ となり, 条件 Cより, $M_{t}\left(\delta\left(s \sigma, x_{0}\right)\right)=$ $M_{t}\left(\delta\left(s^{\prime} \sigma, x_{0}\right)\right)$ である. さらに $M_{t}(\pi(s))=M_{t}\left(\pi\left(s^{\prime}\right)\right)$ より, $M_{t}(\pi(s \sigma))=M_{t}\left(\pi\left(s^{\prime} \sigma\right)\right)$ を得る. Фえに, $K$ の $\left(M_{l}, M_{t}, L(G)\right)$-recognizability より, $s^{\prime} \sigma \in K$ である. 


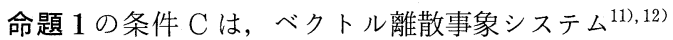
においては常に成り立つ。

定理 1 より, $\left(\Sigma_{u}, L(G)\right)$-不変, $\left(M_{l}, M_{t}, \Sigma_{c}, L(G)\right)-$ 可制御かつ $\left(M_{l}, M_{t}, L(G)\right)$-recognizable である空 でない閉じた言語に対して，スーパバイザが存在する. そこで言語 $K \subseteq L(G)$ に対して, $\left(\Sigma_{u}, L(G)\right)$-不変, $\left(M_{l}, M_{t}, \Sigma_{c}, L(G)\right)$-可制御かつ $\left(M_{l}, M_{t}, L(G)\right)-$ recognizable である閉じたその部分言語の集合を $B(K)$ と書く. $\phi \in B(K)$ より, $B(K)$ は空ではない.

【定理 2】任意の言語 $K \subseteq L(G)$ に対して, 集合 $B(K)$ は集合の和に関して閉じており, その最大要素 $\sup B(K)$ は次式で与えられる.

$$
\sup B(K)=\bigcup_{K^{\prime} \in B(K)} K^{\prime}
$$

（証明） $I$ を任意のインデックス集合とする. 各 $i \in I$ に対して, $K_{i} \in B(K)$ とおく, $\bigcup_{i \in I} K_{i}$ が $\left(\Sigma_{u}, L(G)\right)-$ 不変かつ閉じていることは参考文献 3）で証明されてい る.

まず $\bigcup_{i \in I} K_{i}$ が $\left(M_{l}, M_{t}, L(G)\right)$-recognizable となる ことを示す. $M_{l}(s)=M_{l}\left(s^{\prime}\right), M_{t}(\pi(s))=M_{t}\left(\pi\left(s^{\prime}\right)\right)$ 加 $s \in \bigcup_{i \in I} K_{i}$ なる $s, s^{\prime} \in L(G)$ を考える. このとき， $s \in K_{j}$ なる $j \in I$ が存在する. $K_{j}$ は $\left(M_{l}, M_{t}, L(G)\right)-$ recognizable であるから, $s^{\prime} \in K_{j} \subseteq \bigcup_{i \in I} K_{i}$ である.

つぎに, $\bigcup_{i \in I} K_{i}$ が $\left(M_{l}, M_{t}, \Sigma_{c}, L(G)\right)$-可制御とな ることを証明する. $M_{l}(t)=M_{l}\left(t^{\prime}\right), M_{t}(\pi(t))=$ $M_{t}\left(\pi\left(t^{\prime}\right)\right), t \sigma \in \bigcup_{i \in I} K_{i}$ かつ $t^{\prime} \sigma \in L(G)$ なる $t, t^{\prime} \in$ $\bigcup_{i \in I} K_{i}$ と $\sigma \in \Sigma_{c}$ を考える.このとき， $t \sigma \in K_{k}$ なる $k \in I$ が存在する. $K_{k}$ は閉じているため, $t \in K_{k}$ であ る.そして $K_{k}$ は $\left(M_{l}, M_{t}, L(G)\right)$-recognizable で あるから， $t^{\prime} \in K_{k}$ となる。 また $K_{k}$ は $\left(M_{l}, M_{t}, \Sigma_{c}\right.$, $L(G))$-可制御でもあるので, $t^{\prime} \sigma \in K_{k} \subseteq \bigcup_{i \in I} K_{i}$ を得 る.

ゆえに $B(K)$ は和に関して閉じている．このとき, その最大要素 $\sup B(K)$ が (3) 式で与えられることは 自明である。

\section{5. 例 題}

本節では, Fig. 5 に示す三つの機械 $M_{i}(i=1,2,3)$ により, 二種類のパーツ $p_{j}(j=1,2)$ を加工する簡単な 生産システムを考える。 それぞれのパーツに対して，ま ず $M_{1}$ で最初の加工が行われ， $M_{2}$ むしくは $M_{3}$ によっ て二番目の加工が行われる. $M_{1}$ は Fig. $6, M_{i}(i=2,3)$ はFig. 7 に示されるオートマトンで，それぞれモデル 化されているとする. それぞれの状態と事象の意味は以 下に示す. $x_{i 0}:$ 機械 $M_{i}$ が休止中 $(i=1,2,3)$

$x_{i j}$ : 機械 $M_{i}$ がパーツ $p_{j}$ を加工中 $(i=1,2,3, j=$ $1,2)$

$\alpha_{1 j}$ : 機械 $M_{1}$ がパーツ $p_{j}$ の加工を開始 $(j=1,2)$

$\alpha_{i j}$ : 機械 $M_{1}$ がパーツ $p_{j}$ の加工を終了し, $M_{i}$ が $p_{j}$ の加工を開始 $(i=2,3, j=1,2)$

$\beta_{i}:$ 機械 $M_{i}$ がパーツの加工を終了 $(i=2,3)$

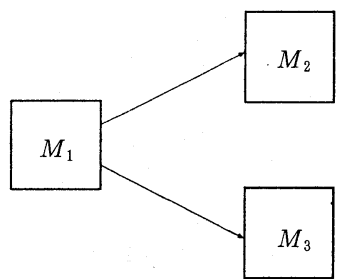

Fig. 5 A simple manufacturing system

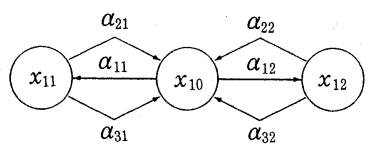

Fig. 6 A state transition diagram of $M_{1}$

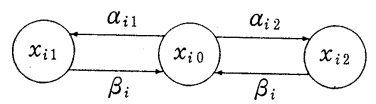

Fig. 7 A state transition diagram of $M_{i}(i=2,3)$

そして全体システムは，これら三つのオートマトンの synchronous composition ${ }^{9)}$ で表現されるとする.こ のときシステムの状態は，それぞれの機械の状態の 3 項 組で表わされる．すなわち状態の集合 $X$ は次式で与え られる。

$$
X=\left\{\left(x_{1}, x_{2}, x_{3}\right) \mid x_{i} \in\left\{x_{i 0}, x_{i 1}, x_{i 2}\right\}\right\}
$$

ここで， $x_{i}$ は機械 $M_{i}$ の状態を表わすとする．そして $\Sigma_{c}=\left\{\alpha_{i j}(i=1,2,3, j=1,2)\right\}$ す なわち各機械の パーッの加工開始のみが禁止できるとする.

ここでは加工された $p_{1}$ と $p_{2}$ の個数の差が常に 1 以下 となり，しかも機械 $M_{2}$ と $M_{3}$ が加工したパーツ数の差 が常に 1 以下となるような公平な制御を考える.このと き，制御仕様 $K \subseteq L(G)$ は次式で与えられる.

$$
\begin{aligned}
K= & \left\{s \in L(G)|\forall t \in \overline{\{s\}} ;| \#\left(t, \alpha_{11}\right)-\#\left(t, \alpha_{12}\right) \mid \leq 1\right. \\
& \wedge \mid\left(\#\left(t, \alpha_{21}\right)+\#\left(t, \alpha_{22}\right)\right) \\
& \left.-\left(\#\left(t, \alpha_{31}\right)+\#\left(t, \alpha_{32}\right)\right) \mid \leq 1\right\}
\end{aligned}
$$


ここで\# $(s, \sigma)$ は系列 $s$ のに $\sigma$ が現れる回数を表わただし，

す. $K$ が $\left(\Sigma_{u}, L(G)\right)$-不変かつ閉じていることは明ら かである.

そして事象と状態に関するマスク $M_{l}$ と $M_{t}$ はそれぞ れ

$$
\begin{aligned}
& M_{l}(\sigma)= \begin{cases}\lambda_{1}, & \text { if } \sigma \in\left\{\alpha_{21}, \alpha_{31}\right\} \\
\lambda_{2}, & \text { if } \sigma \in\left\{\alpha_{22}, \alpha_{32}\right\} \\
\mu, & \text { if } \sigma \in\left\{\beta_{2}, \beta_{3}\right\} \\
\sigma, & \text { otherwise }\end{cases} \\
& M_{t}\left(\left(x_{1}, x_{2}, x_{3}\right)\right)=\left(M_{t 1}\left(x_{1}\right), M_{t 2}\left(x_{2}\right), M_{t 3}\left(x_{3}\right)\right)
\end{aligned}
$$

で与えられるとする.ただし，

$$
M_{t i}\left(x_{i}\right)= \begin{cases}W_{i}, & \text { if } x_{i} \in\left\{x_{i 1}, x_{i 2}\right\} \\ x_{i}, & \text { otherwise }\end{cases}
$$

$$
(i=1,2,3)
$$

である.ここで，

$W_{i}:$ 機械 $M_{i}$ がパーツを加工中 $(i=1,2,3)$

$\lambda_{j}:$ パーツ $p_{j}$ の二番目の加工の開始 $(j=1,2)$

$\mu:$ パーツの二番目の加工の終了

である.

このとき, 事象列 $s=\alpha_{11} \alpha_{21} \beta_{2} \alpha_{12}, s^{\prime}=\alpha_{11} \alpha_{31} \beta_{3} \alpha_{12} \in$ $K$ と $\alpha_{32} \in \Sigma_{c}$ に対して, $M_{l}(s)=M_{l}\left(s^{\prime}\right), s \cdot \alpha_{32} \in K$, $s^{\prime} \alpha_{32} \in L(G)$ かつ $s^{\prime} \alpha_{32} \notin K$ であるから，Kは $\left(M_{l}\right.$, $\left.\Sigma_{c}, L(G)\right)$-可制御ではない. すなわち事象列のみを用 いた従来のスーパバイザは存在しない。しかし $K$ は $\left(M_{l}, M_{t}, \Sigma_{c}, L(G)\right)$-可制御であることが容易に確か められる. よって定理 1 より， $L(S \mid G)=K$ なるスー パバイザ $S: M_{l}(L(G)) \times M_{t}(T(G)) \rightarrow \Gamma$ が存在する.

スーパバイザによって観測される状態の集合は

$$
Y=\left\{\left(y_{1}, y_{2}, y_{3}\right) \mid y_{i} \in\left\{x_{i 0}, W_{i}\right\}(i=1,2,3)\right\}
$$

となり, この $Y$ 上の写像 $V_{i}(i=1,2,3)$ を

$$
V_{i}\left(\left(y_{1}, y_{2}, y_{3}\right)\right)=y_{i}
$$

と定義する. $V_{i}$ を次のように $Y^{*}$ 上の写像に拡張する.

$$
V_{i}\left(y_{(1)} y_{(2)} \cdots y_{(n)}\right)=V_{i}\left(y_{(1)}\right) V_{i}\left(y_{(2)}\right) \cdots V_{i}\left(y_{(n)}\right)
$$

つまり状態の観測列 $e \in M_{t}(T(G))$ に対して, $V_{i}(e)$ は 機械 $i$ に関する状態の観測列を表わす．また $\left(V_{i}(e)\right)$ は, $V_{i}(e)$ において $x_{i 0} W_{i}$ という列が表われる回数, すなわち機械 $i$ が加工したパーツ数を表わすとする.

ここで $L(S \mid G)=K$ なるス一パバイザ $S:$ $M_{l}(L(G)) \times M_{t}(T(G)) \rightarrow \Gamma$ は次式で与えられる.

$$
S(d, e)=S_{1}(d) \cap S_{2}(e)
$$

$$
S_{1}(d)= \begin{cases}\Sigma-\left\{\alpha_{11}\right\}, & \text { if } \#\left(d, \alpha_{11}\right)-\#\left(d, \alpha_{12}\right)=1 \\ \Sigma-\left\{\alpha_{12}\right\}, & \text { if } \#\left(d, \alpha_{12}\right)-\#\left(d, \alpha_{11}\right)=1 \\ \Sigma, & \text { otherwise }\end{cases}
$$

$$
\begin{aligned}
& S_{2}(e) \\
& \quad= \begin{cases}\Sigma-\left\{\alpha_{21}, \alpha_{22}\right\}, & \text { if } \emptyset\left(V_{2}(e)\right)-\emptyset\left(V_{3}(e)\right)=1 \\
\Sigma-\left\{\alpha_{31}, \alpha_{32}\right\}, & \text { if } \emptyset\left(V_{3}(e)\right)-\emptyset\left(V_{2}(e)\right)=1 \\
\Sigma, & \text { otherwise }\end{cases}
\end{aligned}
$$

である。

\section{6. 結 論}

本論文では, 部分観測のもとで, 事象と状態の両方の 観測列を利用したスーパバイザについて考察した。 まず スーパバイザが存在するための必要十分条件を明らかに した。 そして従来のスーパバイザが構成できる言語のク ラスよりあ広いクラスに対して, 本論文で提案したスー パバイザが構成できることを示した．しかし，一般に与 えられた言語に対してスーパバイザが存在するとは限ら ない。そこでスーパバイザが存在するような部分言語を 与えた。

また最近，時間付き離散事象システムに対する制御問 題が重要になってきている ${ }^{14), 15)}$. 本論文で得られた結果 を時間付き離散事象システムに拡張することは今後の検 討課題である.

\section{参 考 文 献}

1) P. J. Ramadge and W. M. Wonham: The Control of Discrete Event Systems ; Proc. of IEEE, Vol. 77, No. 1, pp. 81 98 (1989)

2) 潮：離散事象システムにおける制御問題とスーパバイザ; システム/制御/情報, Vol. 34, No. 9, pp. 531〜538 (1990)

3) P. J. Ramadge and W. M. Wonham : Supervisory Control of a Class of Discrete-Event Processes; SIAM J. Contr. Optimiz., Vol. 25, No. 1, pp. 206 230 (1987)

4) F. Lin and W. M. Wonham : On Observability of Discrete-Event Systems ; Information Sciences, Vol. 44, No. 3, pp. 173 198 (1988)

5) R. Cieslak, C. Desclaux, A. S. Fawaz and P. Varaiya : Supervisory Control of Discrete-Event Processes with Partial Observations; IEEE Trans. Automat. Contr., Vol. 33, No. 3, pp. 249 260 (1988)

6) H. Cho and S. I. Marcus: On Supremal Languages of Classes of Sublanguages that Arise in Supervisor Synthesis Problems with Partial Observation; Math. Control, Signals and Systems, Vol. 2, No. 1, pp. 47 69 (1989)

7) H. Cho and S. I. Marcus : Supremal and Maximal Sublanguages Arising Supervisor Synthesis Problems with Partial Observations; Math. Systems Theory, Vol. 22, No. 3, pp. 177 211 (1989) 
8) R.D. Brandt, V.K. Garg, R. Kumar, F. Lin, S. I. Marcus and W. M. Wonham: Formulas for Calculating Supremal Controllable and Normal Sublanguages ; Systems and Control Letters, Vol. 15, No. 8, pp.111 117 (1990)

9) R. Kumar, V. K. Garg and S. I. Marcus: On Controllability and Normality of Discrete Event Dynamical Systems ; Systems and Control Letters, Vol.17, No.3, pp. 157 168 (1991)

10) R. Kumar: Formulas for Observability of Discrete Event Dynamical Systems : Proc. of the 1993 Conf. on Information Sciences and Systems, pp. 581 586 (1993)

11) Y. Li and W.M. Wonham: Control of Vector DiscreteEvent Systems I-The Base Model; IEEE Trans. Automat. Contr., Vol. 38, No. 8, pp.1214 1227 (1993)

12) Y. Li and W. M. Wonham : Control of Vector DiscreteEvent Systems $\Pi$-Controller Synthesis; IEEE Trans. Automat. Contr., Vol. 39, No. 3, pp. 512 531 (1994)

13) J. E. Hopcroft and J. D. Ullman : Introduction to Automata Theory, Language, and Computation, Addison-Wesley (1979)

14) B. A. Brandin and W. M. Wonham: Supervisory Control of Timed Discrete-Event Systems; IEEE Trans. Automat. Contr., Vol. 39, No. 2, pp. 329 342 (1994)

15) A. Takae, S. Takai, T. Ushio, S. Kumagai and S. Kodama: Maximally Permissive Controllers for Controlled Time Petri Nets; Proc. of the 33rd IEEE CDC, pp.1058 1059 (1994) 